\title{
Decreased biochemical progression in patients with castration-resistant prostate cancer using a novel mefenamic acid anti-inflammatory therapy: A randomized controlled trial
}

\author{
JOSÉ GUZMAN-ESQUIVEL ${ }^{1,2}$, MARTHA A. MENDOZA-HERNANDEZ ${ }^{1}$, DANIEL TIBURCIO-JIMENEZ ${ }^{1}$, \\ OSCAR N. AVILA-ZAMORA ${ }^{3}$, JOSUEL DELGADO-ENCISO ${ }^{4}$, LUIS DE-LEON-ZARAGOZA ${ }^{2,3}$, \\ JUAN C. CASAREZ-PRICE ${ }^{2,3}$, IRAM P. RODRIGUEZ-SANCHEZ ${ }^{5}$, MARGARITA L. MARTINEZ-FIERRO ${ }^{6}$, \\ CARMEN MEZA-ROBLES ${ }^{1,3}$, ALEJANDRO BAROCIO-ACOSTA ${ }^{3}$, LUZ M. BALTAZAR-RODRIGUEZ ${ }^{1}$, \\ SERGIO A. ZAIZAR-FREGOSO ${ }^{1}$, JORGE E. PLATA-FLORENZANO ${ }^{2,3}$ and IVÁN DELGADO-ENCISO ${ }^{1,3}$
}

\author{
${ }^{1}$ Department of Molecular Medicine, School of Medicine, University of Colima, Colima 28040; ${ }^{2}$ Department of Research, \\ General Hospital of Zone No. 1 IMSS, Villa de Alvarez, Colima 28983; ${ }^{3}$ Department of Research, Cancerology State Institute, \\ Colima State Health Services; ${ }^{4}$ Department of Research, Foundation for Cancer Ethics, Education and Research of The \\ Cancerology State Institute, Colima 28085; ${ }^{5}$ Molecular and Structural Physiology Laboratory, \\ School of Biological Sciences, Autonomous University of Nuevo León, Monterrey, Nuevo León 64460; \\ ${ }^{6}$ Molecular Medicine Laboratory, Academic Unit of Human Medicine and Health Sciences, \\ Autonomous University of Zacatecas, Zacatecas 98160, Mexico
}

Received July 19, 2019; Accepted November 13, 2019

DOI: 10.3892/ol.2020.11509

\begin{abstract}
Prostate cancer (PCa) is the second most common non-dermatological cancer in men and is a growing public health problem. Castration-resistant disease (CRD) is the most advanced stage of the disease and is difficult to control. Patients with CRD may no longer accept conventional therapies as they are not in appropriate clinical conditions or they refuse to receive it. Given that inflammation is an essential component of CRD origin and progression, anti-inflammatory agents could be a therapeutic option with fenamates as one of the proposed choices. A prospective, randomized, double-blinded, 2-arm, parallel group, phase II-III clinical trial was performed involving 20 patients with CRD-PCa (with a prostate specific antigen level $<100 \mathrm{ng} / \mathrm{ml}$ ) that were undergoing androgen deprivation therapy (ADT) and did not accept any established treatment for that disease stage. In addition to ADT, 10 patients received placebo and 10 received mefenamic acid $(500 \mathrm{mg}$ orally every $12 \mathrm{~h}$ ) for 6 months. The primary endpoint was the change in serum prostate-specific antigen (PSA) at 6 months. The PSA levels decreased significantly with mefenamic acid (an average $42 \%$ decrease), whereas there was an average $55 \%$
\end{abstract}

Correspondence to: Dr Iván Delgado-Enciso, Department of Molecular Medicine, School of Medicine, University of Colima, Avenue Universidad 333, Colima 28040, Mexico

E-mail: ivan_delgado_enciso@ucol.mx

Keywords: prostate cancer, mefenamic acid, therapy, prostate-specific antigen, clinical trial, nonsteroidal anti-inflammatory drugs increase in the placebo group $(\mathrm{P}=0.024)$. In the patients treated with the placebo, $70 \%$ had biochemical disease progression (an increase of $\geq 25 \%$ in PSA levels), which did not occur in any of the patients treated with mefenamic acid (relative risk $=0.12 ; 95 \%$ confidence interval, $0.01-0.85 ; \mathrm{P}=0.033$ ). There was a significant increase in quality of life (EQ-5D-5L score) and body mass index (BMI) with the experimental treatment. In conclusion, mefenamic acid administration decreased biochemical progression in patients with castration resistant $\mathrm{PCa}$, improved their quality of life and increased their BMI. Future studies are required in order to strengthen the findings of the present clinical trial. Trial registration, Cuban Public Registry of Clinical Trials Database RPCEC00000248, August 2017.

\section{Introduction}

Cancer is one of the leading causes of mortality in a number of high-income countries (1). Prostate cancer (PCa) is the second most common non-dermatological cancer in men (2-5). Based on the 2018 GLOBOCAN estimates, the age-standardized incidence rate was 29.3 per 100,000 standard population, with 1,276,106 new cases registered worldwide (3). Prostate cancer incidence rates are highly variable, with the highest incidence rates having been reported in Oceania (79.1 per 100,000 standard population), followed by North America (73.7) and Europe $(62.1)(3,4)$. PCa is categorized as an androgen-dependent neoplasia (3). Thus, androgen deprivation therapy (ADT) is a commonly prescribed treatment that decreases androgens, such as testosterone to castration levels in an attempt to slow tumor progression and improve overall survival time in men (6). Half of all men with PCa receive ADT at some stage 
following diagnosis (7). When PCa cells acquire the capacity to proliferate without androgens, ADT becomes ineffective and the transition is termed castration-resistant disease (CRD) (8). Bone metastases are present in $90 \%$ of patients with CRD and can produce significant morbidity, including pain, pathological fractures, spinal cord compression and bone marrow failure (9). Paraneoplastic effects due to bone metastases in patients with CRD are also common, such as anemia, weight loss, fatigue, hypercoagulability and increased susceptibility to infection (9).

Radiotherapy and/or chemotherapy are treatment options that can increase the life expectancy of patients with CRD-PCa (10-12); however, they are aggressive treatments that decrease physical independence and can increase weight loss (13-18). Mortality in patients with CRD-PCa has been reported at a median follow-up period of 41 months, generally with a poor quality of life during the last months of life (19). Certain patients with CRD possess adequate knowledge of disease prognosis and the associated consequences, and thus decline the standard treatment and adopt an approach of only taking symptomatological treatment. In these instances, patient autonomy prevails, defined as having the ability to make a rational decision based on the personal understanding of his or her future, and supported by his or her own values (20). The healthcare provider is obligated to respect patient autonomy, if the law does not dictate otherwise.

New treatments, such as those with abiraterone or enzalutamide have shown therapeutic success in metastatic CRD-PCa, although this remains limited (21). Therefore, complementary treatments can still be researched, which can increase the antitumor effect of the implemented therapies or can provide an alternative for patients that are not candidates for conventional therapies $(22,23)$. Anti-inflammatory agents are currently being investigated as a treatment option in different types of neoplasia, such as lung, cervix, ovarian, colon and gastric cancer (24). Inflammation is observed in numerous pathologies, and the current available data demonstrate that it is a critical component in the origin, proliferation and dissemination of different types of cancer, including $\mathrm{PCa}$ (25). In PCa, there is evidence of inflammation in the processes of DNA damage, tumor progression and tumor expansion. Hence, sustained use of nonsteroidal anti-inflammatory drugs (NSAIDs) have been proposed as a mechanism that may retard $\mathrm{PCa}$ disease progression by decreasing the inflammatory response in $\mathrm{PCa}$ cells (25). Observational studies have revealed that NSAIDs are associated with a lower risk of developing PCa (25) and a lower risk of progression to high-grade PCa $(26,27)$, resulting in different NSAIDs being postulated for the treatment of PCa. Clinical trials have been performed with certain NSAIDs (celecoxib, ibuprofen and indomethacin) $(5,28)$, with unsatisfactory results, upon analyzing endpoints such as PSA levels, tumor size or overall survival time $(29,30)$.

Preclinical in vitro and in vivo (xenograft nude mouse model) studies in PCa have demonstrated that the fenamate NSAIDs have a more notable antineoplastic effect compared with previously examined NSAIDs in PCa (31). Mefenamic acid and meclofenamate demonstrate this type of antitumor effect (31). Notably, in a preclinical study, mefenamic acid, a freely sold NSAID whose everyday use is for dysmenorrhea, had a cytotoxic effect on PCa cells at concentrations that can be feasibly achieved in human plasma (31). To the best of our knowledge, the antineoplastic use of a fenamate in humans has not yet been investigated due to advanced tumor stages of PCa, higher PSA levels and weight loss being associated with poor quality of life in patients $(32,33)$. The aforementioned variables provide the rationale for the evaluation of the usefulness of new treatment options in PCa. In the present study the therapeutic effects of mefenamic acid on PSA levels, weight loss and quality of life were investigated in patients with CRD-PCa, who were either not candidates for standard therapy or had declined it.

\section{Patients and methods}

Study design. A prospective, double-blinded, 2-arm, controlled, randomized phase II-III clinical trial was conducted between August 2017 and March 2019. The study was performed according to the CONSORT statement guidelines for randomized controlled trials (34).

The National Commission on Scientific Research (Central Ethics Committee) of the Mexican Social Security Institute (IMSS; Colima, Mexico) approved the present study. Written informed consent was obtained from all participants. The present clinical trial was registered as MEFEPROST: RPCEC00000248 in the Cuban Public Registry of Clinical Trials (RPCEC) Database (http://rpcec.sld.cu). The RPCEC trial registration dataset is part of the International Clinical Trials Platform Registry database, as established by the World Health Organization and the International Committee of Medical Journal Editors.

Study subjects. A total of 46 subjects for the present clinical trial were recruited from the General Hospital Zone 1 of the IMSS and the Cancerology State Institute of the Health Department of the State of Colima (Colima, Mexico).

The following inclusion criteria were used in the present study: Male patients of any age with a histological diagnosis of prostate cancer; patients presenting with CRD according to the Prostate Cancer Clinical Trial Working Group 3 (35), who by their own decision or the clinical opinion of their treating physician, were not candidates for taxane chemotherapy or any other standard first-line treatment for that type of patient; patients whose PSA levels were at stages 1-3 of the D'Amico Risk Classification (1-100 ng/ml) (36); patients undergoing ADT prior to recruitment that was maintained under the treating physician's judgment, during the 6 months of follow-up; patients with an Eastern Cooperative Oncology Status functional status of 0-2 (37) and patients with no history of hepatic impairment (any of the Child-Pugh classification stages) (38) or renal impairment with creatinine clearance $>60 \mathrm{ml} / \mathrm{min}$.

The following exclusion criteria were used in the present study: Diagnosis of a second primary cancer; uncontrolled diabetes or high blood pressure; leukocytes $<3,000$ cells $/ \mu 1$, or a platelet count $<10,000$ cells $/ \mu 1$; leukocytes $>100,000$ cells $/ \mu 1$ or evidence of systemic infection according to the Third International Consensus Definitions for Sepsis and Septic Shock (Sepsis-3) (39); blood hemoglobin $<9 \mathrm{~g} / \mathrm{dl}$; alcoholism and/or drug addiction; gastrointestinal ulcer; inflammatory bowel disease; diagnosis of ischemic heart disease; chronic heart failure and other pathologies at the discretion of the researcher. 
The following elimination criteria were used in the present study: Patients that voluntarily abandoned the study; patients that, at some point during the study, presented with severe toxicity (grade $\geq 3$ ) (40), according to the common terminology criteria for adverse events (CTCAE v4.0; U.S. Department of Health and Human Services) attributable to the administration of the experimental medication (mefenamic acid); and patients in whom the treating physician suspended the experimental medication for $>2$ weeks, regardless of the origin of the adverse event.

Following the application of all the inclusion, exclusion and elimination criteria, 20 patients (57-81 years) were randomized for the present clinical trial. The 6-month intervention consisted of two delivery arms, one with patients receiving mefenamic acid $(n=10)$ and the other with patients receiving placebo $(n=10)$. All patients continued to receive ADT, through the administration of gonadotropin-releasing hormone agonists (leuprolide and goserelin), oral antiandrogens (flutamide and bicalutamide) or through bilateral orchiectomy. The two study groups consisted of one group that took a $500 \mathrm{mg}$ pill of mefenamic acid every $12 \mathrm{~h}$ for 6 months, and another group that took a sugar placebo pill every $12 \mathrm{~h}$ for the same length of time. The pills were recommended to be taken with meals or milk in order to decrease the risk of adverse gastrointestinal events. All patients took one tablet of $20 \mathrm{mg}$ omeprazole daily during the study period to prevent severe acute NSAID-associated gastroduodenal damage.

The treating physician was blinded to the study group the patient belonged to and could prescribe additional treatment if necessary (usual medical care), including radiotherapy for symptom palliation (41).

Outcome measures and patient follow-up. Outcome measures of the present clinical trial were determined, and the primary endpoint was a clinically significant variation in PSA levels in patient blood samples at 6 months. The variation percentage was calculated and the number of patients that had biochemical disease progression was determined through an increase in PSA levels of $\geq 25 \%$, in accordance with the criteria of the Prostate Cancer Clinical Trials Working Group 3. The same was done with respect to the number of patients that had a biochemical therapeutic response defined as a $\geq 50 \%$ decrease in PSA levels (34). Other endpoints of the present trial were the variations in the quality of life score (through the EQ-5D-5L questionnaire) and body mass index (BMI) (42). The previously validated Spanish version of the EQ-5D-5L questionnaire was used in the present study, which evaluates 5 general domains, each one with a score ranging from 0-4 (with a lower score indicating better quality of life) (43). Complete blood count (red and white blood cells), hemoglobin, hematocrit, platelets, kidney (serum creatinine, blood urea nitrogen-BUN-, uric acid) and liver function (albumin, bilirubin, alanine aminotransferase, aspartate aminotransferase, gamma-glutamyl transferase, alkaline phosphatase and lactate dehydrogenase) serum test were monitored in all patients.

Blinding. The researchers who evaluated treatment effectiveness and performed the statistical analyses were blinded to the treatment that the patients received, as were the patients.
Sample size. The sample size calculation was based on the number of treated patients that had biochemical disease progression (a 25\% increase in PSA levels), which was stipulated at $39 \%$ and was performed using ClinCalc online software (version 1; https://clincalc.com/stats/samplesize.aspx). This was based on a previous study on patients with CRD-PCa treated with docetaxel (44). As a comparison figure, it was stipulated that $95 \%$ of the patients with no treatment would present with biochemical disease progression. A total of 10 patients were needed in each arm of the clinical trial to reach the required power $(0.8)$ when the sample size was calculated, using the one-tailed $\alpha(0.05)$. At the end of the study, the statistical power for detecting a difference between the 2 arms of the study was calculated $(\alpha=0.05)$ using the number of patients with disease progression at 6 months in the mefenamic acid group and the placebo group, and the result was $100 \%$.

Statistical analysis. The data are presented as percentages or mean \pm standard error or standard deviation. For inferential statistics, normal data distribution was first determined using the Kolmogorov-Smirnov test and the equality of variances was confirmed using the Levene's test. A paired Student's t-test was employed to compare the numerical variables (with normal distribution) between the 2 groups (mefenamic acid and placebo). The categorical values were compared using the Fisher's exact test or $\chi^{2}$ test. The relative risk (RR), number needed to treat (NNT) and 95\% confidence interval (CI) were calculated to determine the probability of not having disease progression (an increase in serum PSA levels $\geq 25 \%$ ), comparing the mefenamic acid group vs. the placebo group. As the sample size was small, the Laplace/De Morgan correction was employed for the risk analysis, in which 1 was added to each cell of the $2 \times 2$ contingency table (45). The statistical analysis was performed using SPSS 20.0 (IBM Corp), with the exception of the RR and NNT, which were calculated using MedCalc v17.7.2 (MedCalc Software bvba). Sample size and the post-hoc power analysis were calculated using ClinCalc online software. One-tailed $\mathrm{P}<0.05$ was considered to indicate a statistically significant difference.

\section{Results}

Clinical trial flow-process. Of the 46 CRD-PCa patients screened, 20 were randomized into two different study groups, with 10 patients in each group: 10 patients in the mefenamic acid group and 10 patients in the placebo control group. All 20 patients completed the trial (Fig. 1). The clinical characteristics and treatment procedures of the patients are presented in Table I. The results demonstrate that there is no significant difference between the groups, which is the starting point for treatment.

Comparison of the PSA levels in patients treated with mefenamic acid compared with those treated with placebo. Table II presents a comparison between groups for the following variables, PSA, BMI and quality of life. Before and after comparisons between baseline and after 6 months for the same group, for each variable, where evaluated, in order to determine the effects of each treatment. While comparing the percentage change per patient, there was a significant decrease 


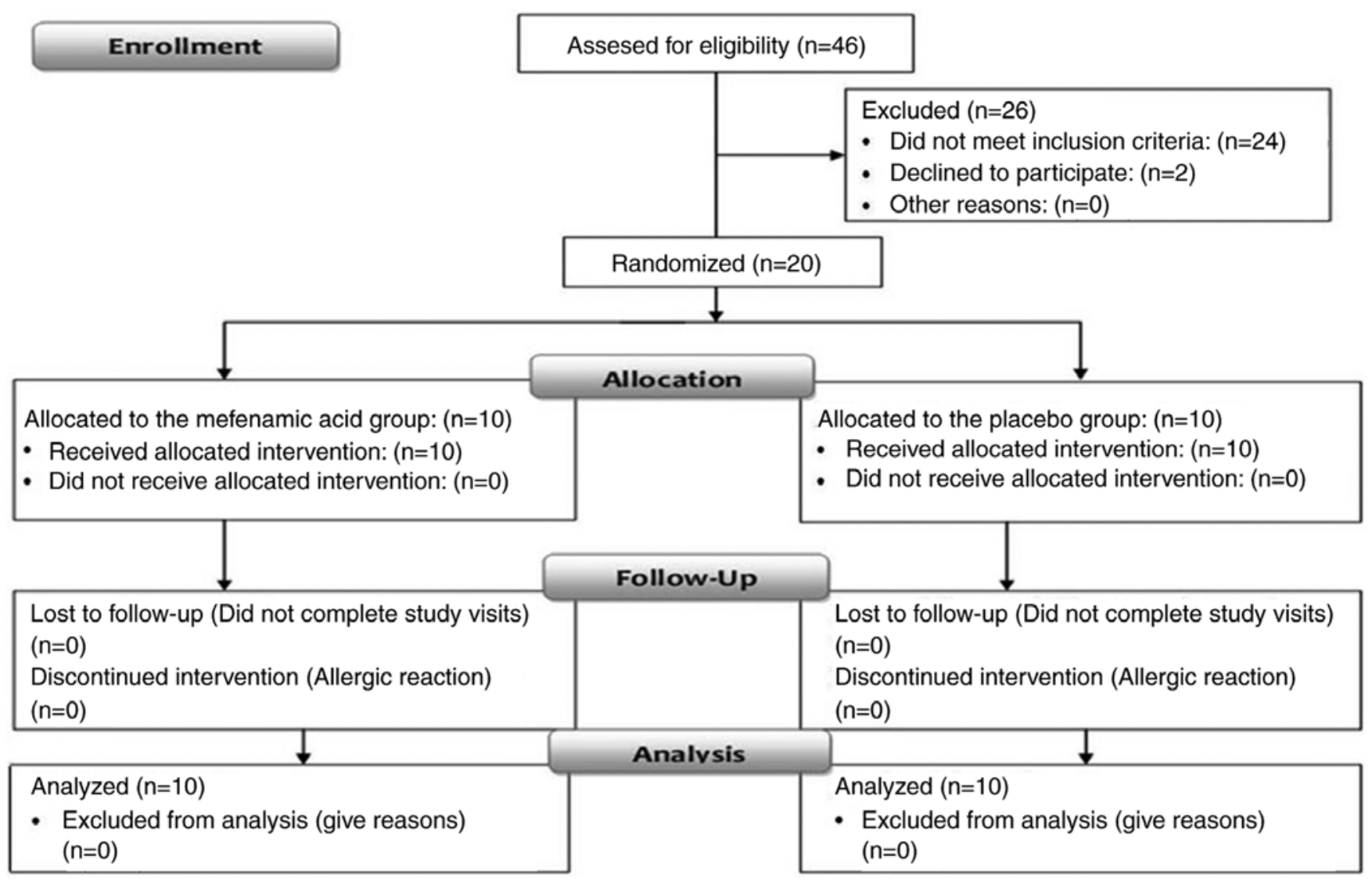

Figure 1. Consort 2010 flow diagram with the number of patients screened, included, eliminated and analyzed in the present study.

in the PSA levels at 6 months of treatment with mefenamic acid (mean decrease of $41.9 \pm 35.8 \%$ ), whereas there was a mean increase in PSA levels in the placebo group of $55.4 \pm 43.1 \%$ (Fig. 2A). Notably, $70 \%$ of the patients in the placebo group exhibited biochemical disease progression (an increase of $\geq 25 \%$ in PSA levels), but this did not occur in any patients treated with mefenamic acid (Fig. 2B).

BMI and quality of life changes in the patients treated with mefenamic acid compared with those treated with placebo. Patients receiving placebo exhibited no changes in their BMI when the baseline and end of trial values were compared $(\mathrm{P}=0.898$; Table II). In contrast, patients in the mefenamic acid arm of the trial had an increased BMI; however, this result was not significant $(\mathrm{P}=0.064$; Table II). A statistically significant difference was observed between the BMI of the patients in the mefenamic acid and placebo groups on completion of the trial $(\mathrm{P}=0.038$; Table II). Quality of life was evaluated using the EQ-5D-5L score, in which a lower score denotes better quality of life. The patients treated with mefenamic acid had a significantly improved quality of life at the end of the study $(\mathrm{P}=0.015$; Table II). The patients treated with placebo had no significant changes in their quality of life at the end of the study ( $\mathrm{P}=0.108$; Table II).

Effects of mefenamic acid on disease progression and therapeutic response in patients with CRD-PCa. The NNT with mefenamic acid to prevent a patient with CRD-PCa and no chemotherapy from presenting with disease progression was
1.71 (Table III). In addition, mefenamic acid administration significantly decreased the probability of biochemical disease progression at 6 months by $88 \%$ compared with the placebo group $(\mathrm{RR}=0.1250 ; 95 \% \mathrm{CI}, 0.0183-0.8515 ; \mathrm{P}=0.0337$; Table III). Even though there was a therapeutic response (a decrease in PSA levels of $\geq 50 \%$ ) in four patients (40\%) with the administration of mefenamic acid, the result was not statistically significant when compared with the placebo group, which had a $0 \%$ therapeutic response $(\mathrm{P}=0.081$; Table III).

Tolerance of clinical trial. Regarding the adverse effects that were potentially associated with the experimental medication, three $(30.0 \%)$ patients presented with abdominal pain/discomfort (gastritis) corresponding to grades 1 and 2 from the CTCAE (40), which is a clinical scale used in cancer trials by clinicians from the National Cancer Institute's based upon symptomatic adverse events at some point during the follow-up, but temporary suspension of the drug ( 2 weeks) was required in only one of the patients. Gastric symptoms ceased on insistence of patients taking the medication with meals. No pathological alterations were observed in the complete blood count or in the kidney and liver function tests of the patients. Experimental treatment was not definitely suspended due to adverse effects in any of the patients.

\section{Discussion}

The present study analyzed the effects of mefenamic acid administration for 6 months in patients with CRD-PCa by 
Table I. Distribution of the main clinical characteristics and treatment procedures of study subjects

\begin{tabular}{|c|c|c|c|}
\hline Clinical characteristics & Mefenamic acid group & Placebo group & P-value \\
\hline Number of patients & 10 & 10 & \\
\hline Age, years (Mean \pm standard deviation) & $71.88 \pm 9.42$ & $67.44 \pm 5.50$ & 0.240 \\
\hline Clinical stage & & & 0.370 \\
\hline IIIA & $40 \%$ & $30 \%$ & \\
\hline IIIB & $20 \%$ & $0 \%$ & \\
\hline IIIC & $10 \%$ & $20 \%$ & \\
\hline IVB & $30 \%$ & $50 \%$ & \\
\hline Diabetes mellitus & $20 \%$ & $40 \%$ & 0.437 \\
\hline High blood pressure & $70 \%$ & $50 \%$ & 0.335 \\
\hline Statins & $30 \%$ & $20 \%$ & 0.563 \\
\hline Hyperlipidemia & $20 \%$ & $30 \%$ & 0.437 \\
\hline Cardiovascular diseases & $50 \%$ & $40 \%$ & 0.581 \\
\hline Antidiabetics & $20 \%$ & $40 \%$ & 0.437 \\
\hline Antiplatelets & $0 \%$ & $20 \%$ & 0.206 \\
\hline Anticoagulants & $10 \%$ & $20 \%$ & 0.735 \\
\hline Antihypertensives & $70 \%$ & $50 \%$ & 0.335 \\
\hline Depression & $10 \%$ & $10 \%$ & 0.735 \\
\hline \multicolumn{4}{|l|}{ Treatments } \\
\hline Radical prostatectomy & $30 \%$ & $10 \%$ & 0.335 \\
\hline Radiotherapy & $10 \%$ & $10 \%$ & 0.735 \\
\hline Other NSAIDs & $0 \%$ & $30 \%$ & 0.082 \\
\hline Surgical castration & $10 \%$ & $0 \%$ & 0.563 \\
\hline \multicolumn{4}{|l|}{ During the study } \\
\hline Radical prostatectomy & $0 \%$ & $0 \%$ & NA \\
\hline Radiotherapy & $10 \%$ & $10 \%$ & 0.735 \\
\hline Chemotherapy & $0 \%$ & $0 \%$ & NA \\
\hline Other NSAIDs & $30 \%$ & $0 \%$ & 0.175 \\
\hline Gastritis & $30 \%$ & $10 \%$ & 0.400 \\
\hline
\end{tabular}

NA, not applicable; NSAIDs, non-steroidal anti-inflammatory drugs.

monitoring tumor progression and quality of life markers. There was a statistically significant $42 \%$ decrease in serum PSA level in the group treated with mefenamic acid compared with the placebo group. In addition, there was an adequate therapeutic response (PSA level decrease of $\geq 50 \%$ ) in $40 \%$ of the patients treated with mefenamic acid. Mefenamic acid also prevented biochemical disease progression.

The percentage of patients treated with mefenamic acid that had a therapeutic biochemical response $(40 \%)$ was similar to that of treatment with abiraterone $(46,47)$ or docetaxel $(48)$. Patients in the present study received abiraterone and docetaxel as part of their normal medical care. The effect of mefenamic acid on biochemical response in the present study was not statistically significant, which maybe attributable to the small sample size of the present study. On the other hand, in the present study, treatment with mefenamic acid significantly prevented biochemical disease progression in patients with CRD-PCa. Mefenamic acid was well-tolerated and no serious adverse effects were reported in the current study, unlike chemotherapy and radiotherapy that can result in considerable adverse effects (49). The abandonment or temporary suspension of treatment with abiraterone and/or chemotherapy is often caused by the presence of adverse effects $(50,51)$. Patients with CRD-PCa do not adequately tolerate conventional treatment regimens due to their clinical condition $(52,53)$. Therefore, the results of the present study pose a benefit and potential alternative therapeutic option for patients with CRD-PCa.

Preclinical and clinical trials have demonstrated that the administration of certain NSAIDs, such as celecoxib does not produce a therapeutic effect $(54,55)$. However, there are reports stating that chronic aspirin consumption lowered PSA levels in patients by $5-10 \%$ at the time of PCa diagnosis, compared with patients that did not take aspirin $(25,27,29)$. To the best of our knowledge, the mechanism by which aspirin decreases PSA levels at the time of diagnosis has not yet been determined, nor has whether that effect is associated with disease progression (56-58). Notably, in the present clinical trial, mefenamic acid was demonstrated to decrease PSA levels when administered to patients with CRD-PCa. Fenamate NSAIDs have been reported to decrease tumor 
Table II. Comparison of body mass index, prostate specific antigen and quality of life (EQ-5D-5L) scores within and between patients in the placebo and mefenamic acid groups.

Time

\begin{tabular}{|c|c|c|c|}
\hline \multirow[b]{2}{*}{ Parameters per group } & \multicolumn{2}{|c|}{ Time } & \multirow[b]{2}{*}{${ }^{b} \mathrm{P}$-value } \\
\hline & $\begin{array}{c}\text { Baseline } \\
(\text { Mean } \pm \text { standard deviation })\end{array}$ & $\begin{array}{c}6 \text { months } \\
\text { (Mean } \pm \text { standard deviation) }\end{array}$ & \\
\hline \multicolumn{4}{|c|}{ Prostate-specific antigen, $\mathrm{ng} / \mathrm{ml}$} \\
\hline Placebo & $10.15 \pm 7.17 \mathrm{ng} / \mathrm{ml}$ & $17.18 \pm 13.04 \mathrm{ng} / \mathrm{ml}$ & 0.012 \\
\hline Mefenamic acid & $7.00 \pm 7.80 \mathrm{ng} / \mathrm{ml}$ & $5.38 \pm 7.80 \mathrm{ng} / \mathrm{ml}$ & 0.018 \\
\hline aP-value & 0.383 & 0.024 & \\
\hline \multicolumn{4}{|l|}{ Body Mass Index } \\
\hline Placebo & $27.70 \pm 1.87$ & $27.70 \pm 3.63$ & 0.898 \\
\hline Mefenamic acid & $30.33 \pm 4.79$ & $32.50 \pm 5.75$ & 0.064 \\
\hline aP-value & 0.112 & 0.038 & \\
\hline \multicolumn{4}{|l|}{ EQ-5D-5L score } \\
\hline Placebo & $6.66 \pm 2.05$ & $5.38 \pm 0.75$ & 0.108 \\
\hline Mefenamic acid & $7.33 \pm 2.00$ & $5.66 \pm 0.66$ & 0.015 \\
\hline${ }^{\text {aP-value }}$ & 0.513 & 0.422 & \\
\hline
\end{tabular}

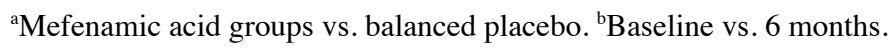
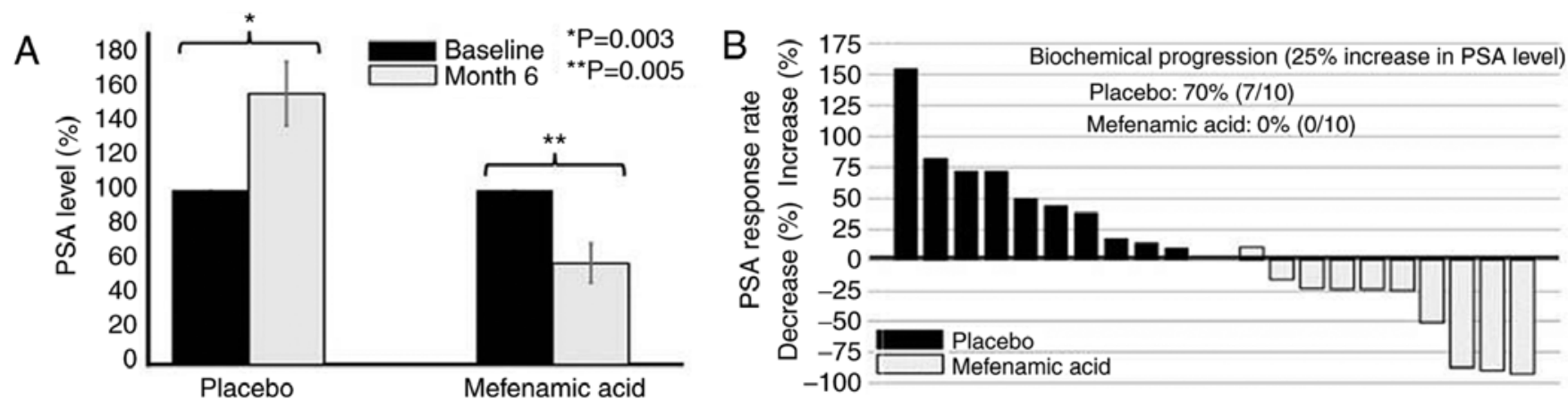

Figure 2. PSA level percentage variations in patients with castration-resistant prostate cancer treated with mefenamic acid and placebo. (A) Comparison of baseline and month 6 PSA levels (\%) within the placebo and mefenamic acid groups. (B) Response rates of patients in the placebo group and mefenamic acid group at follow-up (6 months). PSA, prostate specific antigen.

size and favor apoptosis of PCa cells in in vitro and in vivo models with Foxn1nu mouse strain (31). Different regulatory mechanisms for cell proliferation and their role in cancer have been proposed for mefenamic acid. Previous studies have demonstrated that mefenamic acid is an inhibitor of cyclooxygenase $1(\mathrm{COX}-1)$ and cyclooxygenase 2 (COX-2) isoforms; COX-2 inhibition leads to matriptase inhibition. Matriptase is an enzyme that is responsible for the extent of extracellular matrix degradation. According to a report by Ko et al (59), Cox-2 inhibition hinders PCa cell migration in culture by inhibiting the action of matriptase. In addition, the aforementioned study reported that Cox-2 inhibition produces androgen receptor (AR) inhibition. The AR is vital in the production of prostaglandins, such as prostaglandin e2 (PGE2). At the same time, PGE2 is an autocrine and paracrine lipid signal inducer that functions by binding to the rhodopsin family of G-protein coupled receptors. PGE2 can contribute to tumor development by promoting cell survival, angiogenesis and motility (51).

In addition, mefenamic acid has been demonstrated to induce apoptosis in human cancer cell lines through the caspase-3 pathway (60). Mefenamic acid is also a very potent aldo-keto reductase (AKR) inhibitor (61). AKR enzymes may contribute to the growth of certain types of cancer and their inhibition, particularly of AKR family 1 member C3 (AKR1C3), which potentially exhibits antineoplastic effects (62). Relatively high AKR1C3 mRNA expression was observed in human prostate and mammary glands, where it was involved in regulating ligand access to the androgen and estrogen receptors. AKR1C3 is an interesting target for the development of therapeutic agents for hormone-dependent forms of cancer, such as prostate cancer, breast cancer and endometrial cancer. NSAIDs, specifically indomethacin, celecoxib and fenamates, have been reported as potent inhibitors $(63,64)$. Thus, the 
Table III. Association between mefenamic acid treatment and therapeutic effect.

\begin{tabular}{lccccr}
\hline $\begin{array}{l}\text { Parameters of } \\
\text { therapeutic effect }\end{array}$ & $\begin{array}{c}\text { Mefenamic acid } \\
\text { group }(\%)\end{array}$ & $\begin{array}{c}\text { Placebo } \\
\text { group (\%) }\end{array}$ & RR (95\% CI) & NNT & P-value \\
\hline Response & 40 & 0 & $0.63(0.38-1.05)$ & 3.00 & 0.081 \\
Progression & 0 & 70 & $0.12(0.01-0.85)$ & 1.71 & 0.033 \\
\hline
\end{tabular}

Response is defined $\geq 50 \%$ decrease in PSA levels and progression is defined as $\geq 25 \%$ increase in PSA levels. CI, confidence interval; NNT, number needed to treat; PSA, prostate specific antigen; RR, relative risk.

inhibitory effect of mefenamic acid on AKR1C3 is proposed to be one of its main antineoplastic mechanisms (31). To the best of our knowledge, no previous studies have yet evaluated the antineoplastic effect of mefenamic acid in humans.

Furthermore, patients treated with mefenamic acid had an increased BMI based on the results of the present study and a significant difference was observed between the mefenamic acid and placebo groups. To the best of our knowledge, there are no previous reports that demonstrate that NSAIDs modify body weight. However, this is the first time the drug has been administered for a prolonged period of time. Mefenamic acid has been postulated to significantly increase both carbohydrate absorption and postprandial metabolism in the intestine, through an increase in intestinal blood flow and oxygen consumption (65), which could have been the cause of the weight gain observed in patients in the treatment arm of the present study. Future studies are required in order to confirm the aforementioned results.

There were no changes in quality of life between the placebo and mefenamic acid groups, upon comparing the 5Q-5D-5L scores. Nevertheless, when analyzing the intragroup quality of life scores, only the mefenamic group showed improvement in relation to the baseline scores. This improvement in the mefenamic group could be explained by the treatment with NSAIDS and the consequent decrease in baseline pain levels. According to a recent study, a decrease in pain levels is associated with an improvement in quality of life (66). However, in the present study, there was no statistically significant difference between the baseline and final pain levels measured by the EQ-5D-5L, which is why the effect observed was perhaps not due to a decrease in pain level. On the other hand, there is an association between PSA levels, weight loss and quality of life in patients with prostate cancer (67-69). Therefore, quality of life improvement can be explained by the decrease in PSA levels and the increase in BMI. BMI maintenance is important in patients with cancer. Men with PCa and a BMI $<22.5$ are at greater risk for cancer-specific death (70), and general mortality is twice as great with a body weight loss of more than $5 \%$ in patients with a BMI $<22.5(19)$. Weight loss is the main component of cachexia due to cancer and acts as an indicator of negative energy balance and a pro-inflammatory state (71). The latter decreases the efficacy of antitumor treatment (67). Improvement in quality of life and BMI with NSAID use has been reported in a previous clinical trial (28), concurring with the results of the present study.

Notably, the dose of mefenamic acid administered in the present study ( $1 \mathrm{~g}$ oral dose/day) was lower than the maximum daily recommended dose ( $1.5 \mathrm{~g}$ /day). This lower dose was selected for patients who consumed the drug for a prolonged period of time. There were no serious adverse events reported in the present study due to drug ingestion. Even though no kidney function alterations occurred in patients treated with mefenamic acid, prolonged NSAID use can cause kidney damage (49). This was one of the reasons the decision was made not to administer the drug longer than 6 months.

Another relevant observation is that only patients with PSA levels $<100 \mathrm{ng} / \mathrm{ml}$ were evaluated in the present study and results may be different in patients with higher PSA levels. Future studies investigating patients with $\mathrm{PCa}$ in early clinical stages or hormone-sensitive cancer would be of interest. In preclinical trials, mefenamic acid has been reported to increase the sensitivity of certain types of cancer to chemotherapy and radiotherapy, including colon cancer and lung adenocarcinoma (72). Therefore, future clinical trials to investigate the effect of mefenamic acid in combination with other therapies in patients with PCa are required. PSA kinetics, which is a bone metastasis and survival predictor, was not investigated in the present study (73). However, certain studies have demonstrated contradictory results in PSA kinetics secondary to antineoplastic drug mechanisms (74,75). PSA values at baseline and at 6 months of treatment were investigated for the mefenamic acid and placebo groups in the present study. According to the criteria of the Prostate Cancer Clinical Trials Working Group 3 , this is a useful measurement to determine therapeutic efficacy and tumor progression in clinical trials $(34,76)$.

The present study had limitations, such as small sample size and the length of follow-up. Future studies with a higher number of patients evaluated for a longer period of time with strict monitoring of adverse effects are required in order to confirm the results of the present study.

In conclusion, mefenamic acid administration decreased biochemical progression, increased BMI and improved quality of life in patients with CRD-PCa. Future studies with a higher number of patients investigating the effects of mefenamic acid in combination with other therapies and at different clinical stages of PCa disease, are needed to evaluate its therapeutic potential.

\section{Acknowledgements}

The authors would like to thank postgraduate students Dr. Carlos E. Barajas-Saucedo and Dr. Mario Alberto Gaitan Hinojosa from the Clinical Analysis Laboratory, Faculty of Chemical Sciences, University of Colima (Coquimatlán, 
México), for their assistance in inputting clinical data in different platforms for analysis.

\section{Funding}

The present study was funded by the 2016-FOSISS-CONACYT (grant no. 272792).

\section{Availability of data and materials}

The datasets used and/or analyzed during the present study are available from the corresponding author upon reasonable request.

\section{Authors' contributions}

IDE, JGE, JDE and IRS designed the present study, performed the analyses and drafted the initial manuscript. DTJ, SZF, OAZ, MMH, JCP, ABA, LBR, LLZ and JPF participated in the clinical evaluation of the patients. MMF, DTJ and CMR performed the statistical analyses. JDE was the clinical trial administrative coordinator. All authors read and approved the final manuscript.

\section{Ethics approval and consent to participate}

The study was approved by the National Scientific Commission of the Mexican Social Security Institute (Central Ethics Committee) (R-2018-785-058), and all patients agreed and signed an informed consent form to participate in the study. Patient anonymity was guaranteed in the study. All procedures performed in this protocol were in accordance with The Declaration of Helsinki. The present clinical trial was registered as MEFEPROST: RPCEC00000248 in the Cuban Public Registry of Clinical Trials Database.

\section{Patient consent for publication}

Not applicable.

\section{Competing interests}

The authors declare that they have no competing interests.

\section{References}

1. Hassanipour-Azgomi S, Mohammadian-Hafshejani A, Ghoncheh M Towhidi F, Jamehshorani S and Salehiniya H: Incidence and mortality of prostate cancer and their relationship with the Human Development Index worldwide. Prostate Int 4: 118-124, 2016.

2. Afriansyah A, Hamid ARAH, Mochtar CA and Umbas R: Prostate specific antigen (PSA) kinetic as a prognostic factor in metastatic prostate cancer receiving androgen deprivation therapy: Systematic review and meta-analysis. F1000Res 7: 246, 2018.

3. Rawla P: Epidemiology of prostate cancer. World J Oncol 10: 63-89, 2019.

4. Taitt HE: Global Trends and Prostate cancer: A review of incidence, detection, and mortality as influenced by race, ethnicity, and geographic location. Am J Men's Health 12: 1807-1823, 2018.

5. Adhyam M and Gupta AK: A review on the clinical utility of PSA in cancer prostate. Indian J Surg Oncol 3: 120-129, 2012.

6. Mundell NL, Daly RM, Macpherson H and Fraser SF: Cognitive decline in prostate cancer patients undergoing ADT: A potential role for exercise training. Endocr Relat Cancer 24: R145-R155, 2017.
7. McHugh DJ, Root JC, Nelson CJ and Morris MJ: Androgendeprivation therapy, dementia, and cognitive dysfunction in men with prostate cancer: How much smoke and how much fire? Cancer 124: 1326-1334, 2018.

8. Maughan BL, Antonarakis ES and Hopkins Sidney Kimmel J: Androgen pathway resistance in prostate cancer and therapeutic implications HHS Public Access. Expert Opin Pharmacother 16: 1521-1537, 2015.

9. Hotte SJ and Saad F: Current management of castrate-resistant prostate cancer. Curr Oncol 17 (Suppl 2): S72-S79, 2010.

10. Nader R, El Amm J and Aragon-Ching JB: Role of chemotherapy in prostate cancer. Asian J Androl 20: 221-229, 2018.

11. Sichero L and Villa LL: Epidemiological and functional implications of molecular variants of human papillomavirus. Brazilian J Med Biol Res 39: 707-717, 2006.

12. Handy CE and Antonarakis ES: Sequencing treatment for castration-resistant prostate cancer. Curr Treat Options Oncol 17: 64, 2016.

13. Vanagas G, Mickevičienè A and Ulys A: Does quality of life of prostate cancer patients differ by stage and treatment? Scand J Public Health 41: 58-64, 2013.

14. Farris MS, Kopciuk KA, Courneya KS, McGregor SE, Wang Q and Friedenreich CM: Identification and prediction of health-related quality of life trajectories after a prostate cancer diagnosis. Int J Cancer 140: 1517-1527, 2017.

15. Charalambous $A$ and Kouta C: Cancer related fatigue and quality of life in patients with advanced prostate cancer undergoing chemotherapy. Biomed Res Int 2016: 3989286, 2016.

16. Dun YJ, Liu HX, Yu LP,Li Q,Zhang XW, Tang X, Qin CP and Xu T: Development and initial validation of the novel scale for assessing quality of life of prostate cancer patients receiving androgen deprivation therapy. Chin Med J (Engl) 130: 2082-2087, 2017.

17. Chambers SK, Ng SK, Baade P, Aitken JF, Hyde MK, Wittert G, Frydenberg M and Dunn J: Trajectories of quality of life, life satisfaction, and psychological adjustment after prostate cancer. Psychooncology 26: 1576-1585, 2017.

18. Jang JW, Drumm MR, Efstathiou JA, Paly JJ, Niemierko A, Ancukiewicz M, Talcott JA, Clark JA and Zietman AL: Long-term quality of life after definitive treatment for prostate cancer: Patient-reported outcomes in the second posttreatment decade. Cancer Med 6: 1827-1836, 2017.

19. Griffin K, Csizmadi I, Howard LE, Pomann GM, Aronson WJ, Kane CJ, Amling CL, Cooperberg MR, Terris MK, Beebe-Dimmer J and Freedland SJ: First-year weight loss with androgen-deprivation therapy increases risks of prostate cancer progression and prostate cancer-specific mortality: Results from SEARCH. Cancer Causes Control 30: 259-269, 2019.

20. Valente SM: End-of-life challenges: Honoring autonomy. Cancer Nurs 27: 314-319, 2004.

21. Attard G,Borre M,Gurney H,Loriot Y,Andresen-DaniilC,Kalleda R, Pham T and Taplin ME; PLATO collaborators: Abiraterone alone or in combination with enzalutamide in metastatic castration-resistant prostate cancer with rising prostate-specific antigen during enzalutamide treatment. J Clin Oncol 36: 2639-2646, 2018.

22. Haberkorn U, Eder M, Kopka K, Babich JW and Eisenhut M: New strategies in prostate cancer: Prostate-specific membrane antigen (PSMA) ligands for diagnosis and therapy. Clin Cancer Res 22: 9-15, 2016.

23. Sumanasuriya $\mathrm{S}$ and De Bono J: Treatment of advanced prostate cancer-a review of current therapies and future promise. Cold Spring Harb Perspect Med 8: a030635, 2018.

24. Yiannakopoulou E: Targeting epigenetic mechanisms and microRNAs by aspirin and other non steroidal anti-inflammatory agents-Implications for cancer treatment and chemoprevention. Cell Oncol (Dordr) 37: 167-178, 2014.

25. Ma Y and Brusselaers N: Maintenance use of aspirin or other non-steroidal anti-inflammatory drugs (NSAIDs) and prostate cancer risk. Prostate Cancer Prostatic Dis 21: 147-152, 2018.

26. Algotar AM, Behnejad R, Stratton MS and Stratton SP: Chronic use of NSAIDs and/or statins does not affect PSA or PSA velocity in men at high risk for prostate cancer. Cancer Epidemiol Biomarkers Prev 23: 2196-2198, 2014.

27. Manley G: Aspirin, NSAID and risk of prostate cancer: Results from the REDUCE study. Clin Cancer Res 71: 233-236, 2013.

28. Solheim TS, Fearon KC, Blum D and Kaasa S: Non-steroidal anti-inflammatory treatment in cancer cachexia: A systematic literature review. Acta Oncol 52: 6-17, 2013.

29. Veitonmäki T, Murtola TJ, Talala K, Taari K, Tammela T and Auvinen A: Non-steroidal anti-inflammatory drugs and cancer death in the finnish prostate cancer screening trial. PLoS One 11: e0153413, 2016. 
30. Flamiatos JF, Beer TM, Graff JN, Eilers KM, Tian W, Sekhon HS and Garzotto M: Cyclooxygenase-2 (COX-2) inhibition for prostate cancer chemoprevention: double-blind randomised study of pre-prostatectomy celecoxib or placebo. BJU Int 119: 709-716, 2017.

31. Soriano-Hernández AD, Galvan-Salazar HR, Montes-Galindo DA, Rodriguez-HernandezA,Martinez-Martinez R, Guzman-EsquivelJ, Valdez-Velazquez LL, Baltazar-Rodriguez LM, Espinoza-Gómez F, Rojas-Martinez A, et al: Antitumor effect of meclofenamic acid on human androgen-independent prostate cancer: A preclinical evaluation. Int Urol Nephrol 44: 471-477, 2012.

32. Bonn SE, Wiklund F, Sjölander A, Szulkin R, Stattin P, Holmberg E, Grönberg H and Bälter K: Body mass index and weight change in men with prostate cancer: Progression and mortality. Cancer Causes Control 25: 933-943, 2014.

33. Jackson SE, Heinrich M, Beeken RJ and Wardle J: Weight loss and mortality in overweight and obese cancer survivors: A systematic review. PLoS One 12: 1-21, 2017.

34. Pandis N, Chung B, Scherer RW, Elbourne D and Altman DG: CONSORT 2010 statement: Extension checklist for reporting within person randomised trials. BMJ 357: j2835, 2017.

35. Scher HI, Morris MJ, Stadler WM, Higano C, Basch E, Fizazi K Antonarakis ES, Beer TM, Carducci MA, Chi KN, et al: Trial design and objectives for castration-resistant prostate cancer: Updated recommendations from the prostate cancer clinical trials working Group 3. J Clin Oncol 34: 1402-1418, 2016.

36. Hernandez DJ, Nielsen ME, Han M and Partin AW: Contemporary evaluation of the D'amico risk classification of prostate cancer. Urology 70: 931-935, 2007.

37. Oken MM, Creech RH, Tormey DC, Horton J, Davis TE, McFadden ET and Carbone PP: Toxicity and response criteria of the eastern cooperative oncology Group. Am J Clin Oncol 5: $649-655,1982$

38. Kok B and Abraldes J: Child-pugh classification: Time to abandon? Semin Liver Dis 39: 96-103, 2019.

39. Singer M, Deutschman CS, Seymour CW, Shankar-Hari M, Annane D, Bauer M, Bellomo R, Bernard GR, Chiche JD, Coopersmith CM, et al: The third international consensus definitions for sepsis and septic shock (Sepsis-3). Jama 315 801-810, 2016

40. Dueck AC, Mendoza TR, Mitchell SA, Reeve BB, Castro KM, Rogak LJ, Atkinson TM, Bennett AV, Denicoff AM, O'Mara AM, et al: Validity and reliability of the US national cancer institute's patient-reported outcomes version of the common terminology criteria for adverse events (PRO-CTCAE). JAMA Oncol 1: 1051-1059, 2015.

41. Lutz S, Berk L, Chang E, Chow E, Hahn C, Hoskin P, Howell D, Konski A, Kachnic L, Lo S, et al: Palliative radiotherapy for bone metastases: An ASTRO evidence-based guideline. Int J Radiat Oncol Biol Phys 79: 965-976, 2011.

42. Blanchard CM, Stein K and Courneya KS: Body mass index, physical activity, and health-related quality of life in cancer survivors. Med Sci Sports Exerc 42: 665-671, 2010.

43. Hernandez G, Garin O, Pardo Y, Vilagut G, Pont À, Suárez M, Neira M, Rajmil L, Gorostiza I, Ramallo-Fariña Y, et al: Validity of the EQ-5D-5L and reference norms for the Spanish population. Qual Life Res 27: 2337-2348, 2018.

44. Zhao J, Shen P, Sun G, Chen N, Liu J, Tang X, Huang R, Cai D, Gong J, Zhang X, et al: The prognostic implication of intraductal carcinoma of the prostate in metastatic castration-resistant prostate cancer and its potential predictive value in those treated with docetaxel or abiraterone as first-line therapy. Oncotarget 8: 55374-83, 2017.

45. Greenland S: Small-sample bias and corrections for conditional maximum-likelihood odds-ratio estimators. Biostatistics 1: $113-122,2000$

46. de Bono JS, Logothetis CJ, Molina A, Fizazi K, North S, Chu L, Chi KN, Jones RJ, Goodman OB Jr, Saad F, et al: Abiraterone and increased survival in metastatic prostate cancer. $\mathrm{N}$ Engl $\mathrm{J}$ Med 364: 1995-2005, 2011

47. Chang LW, Hung SC, Wang SS, Li JR, Yang CK, Chen CS Ho HC, Cheng CL and Ou YC CK: Abiraterone acetate and enzalutamide: Similar efficacy in treating post docetaxel metastatic castration-resistant prostate cancer: Single center experience. Anticancer Res 39: 3901-3908, 2019.

48. Yamashita S, Kohjimoto Y, Iguchi T, Koike H, Kusumoto H, Iba A, Kikkawa K, Kodama Y, Matsumura N and Hara I: Prognostic factors and risk stratification in patients with castration-resistant prostate cancer receiving docetaxel-based chemotherapy. BMC Urol 16: 13, 2016.
49. Harirforoosh S, Asghar W and Jamali F: Adverse effects of nonsteroidal antiinflammatory drugs: An update of gastrointestinal, cardiovascular and renal complications. J Pharm Pharm Sci 16: 821-847, 2013

50. Mimeault M, Johansson SL, Henichart JP, Depreux P and Batra SK: Cytotoxic effects induced by docetaxel, gefitinib, and cyclopamine on side population and nonside population cell fractions from human invasive prostate cancer cells. Mol Cancer Ther 9: 617-630, 2010.

51. Baker J, Ajani J, Scotté F, Winther D, Martin M, Aapro MS and von Minckwitz G: Docetaxel-related side effects and their management. Eur J Oncol Nurs 13: 49-59, 2009.

52. Climent MA, Torregrosa MD, Vázquez S, Gironés R and Arranz JA: Aged patients with metastatic castration resistant prostate cancer: Should we treat with chemotherapy? Cancer Treat Rev 55: 173-80, 2017.

53. Benidir T, Hersey K, Finelli A, Hamilton R, Joshua AM, Kulkarni G, Zlotta A and Fleshner N: Understanding how prostate cancer patients value the current treatment options for metastatic castration resistant prostate cancer. Urol Oncol 36: 240.e13-240.e20, 2018.

54. Gupta S, Adhami VM, Subbarayan M, MacLennan GT, Lewin JS, Hafeli UO, Fu P and Mukhtar H: Suppression of prostate carcinogenesis by dietary supplementation of celecoxib in transgenic adenocarcinoma of the mouse prostate model. Cancer Res 64: 3334-3343, 2004.

55. James ND, Sydes MR, Mason MD, Clarke NW, Anderson J, Dearnaley DP, Dwyer J, Jovic G, Ritchie AW, Russell JM, et al: Celecoxib plus hormone therapy versus hormone therapy alone for hormone-sensitive prostate cancer: first results from the STAMPEDE multiarm, multistage, randomised controlled trial. Lancet Oncol 13: 549-558, 2012.

56. Algotar AM, Thompson PA, Ranger-Moore J, Stratton MS, Hsu CH, Ahmann FR, Nagle RB and Stratton SP: Effect of aspirin, other NSAIDs, and statins on PSA and PSA velocity. Prostate 70: 883-888, 2010.

57. Derry S, Wiffen PJ, Moore R, McNicol ED, Bell RF, Carr DB, McIntyre $\mathrm{M}$ and Wee B: Oral nonsteroidal anti-inflammatory drugs (NSAIDs) for cancer pain in adults. Cochrane Database Syst Rev 7: CD012638, 2017.

58. SingerEA,Palapattu GS and Van Wijngaarden E: Prostate-specific antigen levels in relation to consumption of nonsteroidal anti-inflammatory drugs and acetaminophen: Results from the 2001-2002 National Health and Nutrition Examination Survey. Cancer 113: 2053-2057, 2008

59. Ko CJ, Lan SW, Lu YC, Cheng TS, Lai PF, Tsai CH, Hsu TW, Lin HY, Shyu HY, Wu SR, et al: Inhibition of cyclooxygenase-2-mediated matriptase activation contributes to the suppression of prostate cancer cell motility and metastasis. Oncogene 36: 4597-609, 2017.

60. Woo DH, Han IS and Jung G: Mefenamic acid-induced apoptosis in human liver cancer cell-lines through caspase-3 pathway. Life Sci 75: 2439-2449, 2004.

61. Penning TM, Steckelbroeck S, Bauman DR, Miller MW, Jin Y, Peehl DM, Fung KM and Lin HK: Aldo-keto reductase (AKR) 1C3: Role in prostate disease and the development of specific inhibitors. Mol Cell Endocrinol 248: 182-191, 2006.

62. Škarydová L, Živná L, Xiong G, Maser E and Wsól V: AKR1C3 as a potential target for the inhibitory effect of dietary flavonoids. Chem Biol Interact 178: 138-144, 2009.

63. Bauman DR, Rudnick SI, Szewczuk LM, Jin Y, Gopishetty S and Penning TM: Development of nonsteroidal anti-inflammatory drug analogs and steroid carboxylates selective for human aldo-keto reductase isoforms: Potential antineoplastic agents that work independently of cyclooxygenase isozymes. Mol Pharmacol 67: 60-68, 2005.

64. Soriano-Hernández AD, Madrigal-Pérez D, Galván-Salazar HR, Martínez-Fierro ML, Valdez-Velazquez LL, Espinoza-Gómez F, Vazquez-Vuelvas OF, Olmedo-Buenrostro BA, Guzman-Esquivel J, Rodriguez-Sanchez IP, et al: Anti-inflammatory drugs and uterine cervical cancer cells: Antineoplastic effect of meclofenamic acid. Oncol Lett 10: 2574-2578, 2015.

65. Gallavan RH Jr and Chou CC: The effects of mefenamic acid on postprandial intestinal carbohydrate metabolism. Prostaglandins 31: 1069-1076, 1986.

66. Gaertner J, Stamer UM, Remi C, Voltz R, Bausewein C, Sabatowski R, Wirz S, Müller-Mundt G, Simon ST, Pralong A, et al: Metamizole/dipyrone for the relief of cancer pain: A systematic review and evidence-based recommendations for clinical practice. Palliat Med 31: 26-34, 2017. 
67. Chen SS, Cheng TC, Chiu LP, Tasi LY, Huang SS and Tsay SL: Predictors for lower urinary tract symptoms and the urinary specific quality of life in prostate cancer patients: One-year follow-up. J Chinese Med Assoc 82: 482-487, 2019.

68. Vagnildhaug OM, Blum D, Wilcock A, Fayers P, Strasser F, Baracos VE, Hjermstad MJ, Kaasa S, Laird B, Solheim TS, et al: The applicability of a weight loss grading system in cancer cachexia: A longitudinal analysis. J Cachexia Sarcopenia Muscle 8: 789-797, 2017.

69. Kelly SP, Graubard BI, Andreotti G, Younes N, Cleary SD and Cook MB: Prediagnostic body mass index trajectories in relation to prostate cancer incidence and mortality in the PLCO cancer screening trial. J Natl Cancer Inst 109, 2016.

70. Cantarutti A, Bonn SE, Adami HO, Grönberg H, Bellocco R and Bälter K: Body mass index and mortality in men with prostate cancer. Prostate 75: 1129-1136, 2015.

71. Reid J, Hughes CM, Murray LJ, Parsons C and Cantwell MM: Non-steroidal anti-inflammatory drugs for the treatment of cancer cachexia: A systematic review. Palliat Med 7: 295-303, 2013.
72. Kobayashi S, Okada S, Yoshida H and Fujimura S: Indomethacin Enhances the Cytotoxicity of VCR and ADR in human pulmonary adenocarcinoma cells. Tohoku J Exp Med 181: 361-370, 1997.

73. Kim JK, Jeong CW, Ku JH, Kim HH and Kwak C: Prostate specific antigen (PSA) persistence 6 weeks after radical prostatectomy and pelvic lymph node dissection as predictive factor of radiographic progression in node-positive prostate cancer patients. J Cancer 10: 2237-2242, 2019.

74. Kanzaki H, Kataoka M, Nishikawa A, Uwatsu K, Nagasaki K, Nishijima $\mathrm{N}$ and Hashine K: Kinetics differences between PSA bounce and biochemical failure in patients treated with 125I prostate brachytherapy. Jpn J Clin Oncol 45: 688-694, 2015.

75. Fenner A: Prostate cancer: PSA kinetics predict survival in patients treated with abiraterone. Nat Rev Urol 12: 240, 2015

76. Takeuchi H, Ohori M and Tachibana M: Clinical significance of the prostate-specific antigen doubling time prior to and following radical prostatectomy to predict the outcome of prostate cancer. Mol Clin Oncol 6: 249-254, 2017. 